\section{Premarital Sex, Safer Sex and Factors Influencing Premarital Sex Practices Among Senior Secondary School Students in Ebonyi Local Government Area of Ebonyi State Nigeria}

\author{
Alo Chihurumnanya ${ }^{1 *}$, Ogbonnaya Lawrence $U^{1}$, Azuogu \\ Benedict $\mathbf{N}^{1}$, Duvie Uche ${ }^{1}$ and Omaka Nnenna $\mathrm{AL}^{2}$ \\ ${ }^{1}$ Department of Community Medicine, Faculty of Medicine, Ebonyi State \\ University, Abakaliki, Ebonyi State, Nigeria
}

${ }^{2}$ Department of Human Kinetics and Health Education, Ebonyi State University, Abakaliki, Ebonyi State, Nigeria

\begin{abstract}
Introduction: Premarital sex or penetrative sex before marriage has consequences on adolescents because youths who begin sexual activity earlier appear more likely to have sex with high-risk partners, multiple partners and are less likely to use condoms, while safer sex is sexual activity engaged in by people who have taken precautions to protect themselves against sexually transmitted infections. The objectives of this study was to evaluate the prevalence of premarital sex, knowledge and practice of safer sex and reasons for practicing premarital sex among senior secondary school students in Ebonyi Local Government Area of Ebonyi State.

Materials and methods: Cross sectional study involving 398 secondary school students selected by multi stage sampling method. A pre-tested, semi-structured, self-administered questionnaire was used to collect data which was analyzed using SPSS version 16.

Results: Among 392 respondents, 154 (39.3\%) were males and $238(60.7 \%)$ were females. Mean age and standard deviation was $17.1 \pm 1.6$. One hundred and eight $(27.6 \%)$ of the respondents engaged in premarital sex; males $58(37.7 \%)$ more than the females $50(21.0 \%)$. One hundred and seventy two $(43.9 \%)$ were aware of safer sex of which $98(57.0 \%)$ had correct knowledge of it. Factors influencing premarital sex among them were exposure to eroticism
\end{abstract}

*Corresponding author: Alo Chihurumnanya, Department of Community Medicine, Faculty of Medicine, Ebonyi State University, Abakaliki, Ebony State, Nigeria, Tel: +234 8026777800; E-mail: chihurumnanyalo@gmail.com docaloii@yahoo.com

Citation: Chihurumnanya A, Lawrence UO, Benedict NA, Uche D, Nnenna ALO (2016) Premarital Sex, Safer Sex and Factors Influencing Premarita Sex Practices Among Senior Secondary School Students in Ebonyi Local Government Area of Ebonyi State Nigeria. J Community Med Public Health Care 3: 012.

Received: August 11, 2015; Accepted: December 28, 2015; Published: January 11, 2016
$27(32.4 \%)$, sexual desire $63(16.0 \%)$, peer pressure $58(14.8 \%)$, etc.

Conclusion: Premarital sex was practiced among the students yet few of them knew and practiced safer sex. Males were significantly more likely to engage in premarital sex than females in the adolescent period. The most prevalent reason why they practiced premarital sex was exposure to eroticism through television, magazines and the internet.

Keywords: Pre-marital sex; Safer sex; Secondary school; Students

\section{Introduction}

Premarital sex or penetrative sex before marriage and its consequences on adolescent's health has generated a lot of concerns among policy makers, researchers and even religious leaders. In many countries of the world for example in North America, the personal responsibility and work opportunity reconciliation act enacted in 1996 contained a funding for abstinence-until-marriage education [1]. Programs funded under the act must teach that "abstinence from sexual activity outside marriage is the expected standard" of behaviour and that sexual activity outside of the context of marriage is likely to have harmful psychological and physical effects [1] in North America. Almost all Americans have had premarital sex [1]. In India, HIV prevention efforts among the young are on the increase because it has been shown that about $21.7 \%$ of males and $6.3 \%$ of females become sexually active before marriage [2]. Elsewhere in Africa, the prevalence of premarital sex was found to be $32 \%$ among the young [3]. In $2008,20 \%$ of women in Nigeria were already sexually active by age 15, and the median age for first sex stood at 17.7 years for women and 20.6 years for men [4]. Another study in South West Nigeria reported premarital sex prevalence of $28.3 \%$ among adolescents [5]. This stirs up a lot of concern because it has been shown that early sexual initiation lengthens the period of exposure to unwanted pregnancies, HIV, and other sexually transmitted infections [2]. Youths who begin sexual activity earlier appear more likely to have sex with high-risk partners or multiple partners and are less likely to use condoms [6].

Safe sex on the other hand is sexual activity engaged in by people who have taken precautions to protect themselves against sexually transmitted infections such as Human Immunodeficiency Virus/Acquired Immune Deficiency Syndrome, (HIV/AIDS) [7]. It is also referred to as safer sex or protected sex [4]. Safe sex is regarded as a harm reduction strategy aimed at reducing risk $[8,9]$. The concept includes the limiting of number of sexual partners, using prophylactics, avoiding body fluid exchange and resisting the use of drugs that reduce inhibitions for high-risk sexual behaviour [10]. Adolescence represents a transition from childhood to adulthood with features including secondary sexual growth changes in hormonal milieu, emotional, cognitive and psychological development [11]. Adolescents are usually adventurous in all spheres of human endeavours including sexual practices [12]. Their sexual attitude to sexual health continues to change in ways that potentially put their health generally at risk. The environment in which young people are growing up places a greater pressure on the acquisition of skills, the consequences of early sex and pregnancy may be more severe than 
they were in the past [12]. These consequences are potentially more problematic for girls, who are more vulnerable to Sexually Transmitted Diseases (STDs), and HIV/AIDS and unwanted pregnancy [12]. When they become pregnant, they shoulder all of the burden of premarital childbearing and even most of the cost of child rearing [12], delaying the initiation of intercourse has significant personal and public health benefit, particularly for the youngest adolescents [2]. These benefits include protection against unwanted pregnancy, unsafe abortions, STDs and HIV/AIDS [1]. Unfortunately, few rigorously evaluated programs have been able to demonstrate success in delaying the initiation of sexual intercourse [6]. Recent WHO report also showed that many of them had engaged in risky sexual activity without protection and most had that debut through a subtle coercion by their partners. This practice commonly resulted in sexually transmitted infections, unwanted pregnancy and unsafe abortions [5]. The objectives of this study was to evaluate the prevalence of premarital sex, knowledge and practice of safer sex and also reasons for which adolescents practice premarital sex among senior secondary school students in Ebonyi Local Government Area of Ebonyi State South East Nigeria.

\section{Materials and Methods}

This study was carried out in Government owned Secondary schools in Ebonyi Local Government area of Ebonyi state. There are 12 Government owned Secondary schools in Ebonyi Local Government Area. Eleven of these schools are co-educational while only one is a girl's school. The study was carried out among the co-educational schools. This was a descriptive cross sectional study carried out in October 2012. Sample size was calculated using the statistical formulae for sample size calculation $\left(n=Z^{2} \mathrm{Pq} / \mathrm{d}^{2}\right)$ when population is less than $10,000 . Z=1.96, P=0.5$ (estimated), $q=1-0.5$ and $\mathrm{d}$ was set at 0.05 . Applying the values to the formula,

$$
\begin{aligned}
& \mathrm{n}=(1.96)^{2} \times 0.5(1-0.5) /(0.05)^{2} \\
& \mathrm{n}=3.8416 \times 0.5 \times 0.5 / 0.0025 \\
& \mathrm{n}=0.9604 / 0.0025 \\
& \mathrm{n}=384.16 \approx 384 .
\end{aligned}
$$

Because the researchers were going to wait on the students to retrieve all the questionnaires, they anticipated a very low non-response rate of about $4 \%$.

Therefore, $\mathrm{n}=384+(0.04 \times 384)=384+15.36=399.36 \approx 400$.

Having arrived at a sample size of 400 , four schools among the co-educational schools were selected using simple random sampling technique. The schools had a total of 925 students in the senior secondary class with a range of 210 to 250 students in their enrolment. School 'A' had 210 senior secondary students, school 'B' had 225 senior secondary students, school ' $C$ ' had 240 senior secondary students, while school ' $D$ ' had 250 senior secondary students in their enrolments respectively. In the second stage of the sampling, 100 students each were selected from the class register using systematic random sampling technique. This was done using the enrolment register. For example in the school with 210 students, a sampling interval of two was used to select 100 respondents from the senior secondary class lists.

Permission was obtained from the principals of the schools and students who were selected to participate in the survey were properly informed on the subject matter and had the freedom to decline from participation. The students were also made to understand that their responses will not be divulged to anyone else and that the responses were for the purposes of research only. Consenting students indicated so by checking the "I agree" option on the introductory part of the questionnaire which required prospective participants to either agree or disagree with participation in the survey. Those who selected "I disagree" did not participate in the survey and thus were replaced by selecting the next eligible respondent.

The questionnaire was a self-administered, paper based questionnaire developed for the purposes of finding out the number of students who engage in premarital sex, their knowledge of safer sex practices and the reasons why they practice premarital sex. The questionnaire was semi-structured in that some questions were open ended and others were closed ended. The questions on demographic characteristics were open ended while the questions that assessed practice, knowledge and reasons for engaging in premarital sex were structured. The questions were developed using some literatures $[13,14]$ and also from prevailing anecdotal environmental and social circumstances in Ebonyi Local Government. The questionnaire was pretested in a Secondary school in another Local Government Area. The pre-test helped to re-structure ambiguous questions to clearer questions and options.

Sociodemographic characteristic: the sociodemographic characteristics assessed include age, sex, class, religion, and who the student lives with (parents, guardian or living alone).

Practice and prevalence of premarital sex: this was assessed by asking the students what they understand premarital sex to be. The following options were provided; "sex with someone you know", "sex with someone you do not know", "sex with someone you love" "sex with someone you are co-habiting with", "sex with someone whom you are engaged to", "sex with someone who has proposed to marry you", and "sex with someone who is married to you". Multiple responses were allowed here. Other questions posed were "have you had sex before?", and "when was the last time you had sex"? Here, options were provided such as; 'more than three months ago' and 'within the last three months'

Awareness of safer sex was assessed by asking the following closed ended questions with options: safer sex is "sex using condom correctly and consistently", "sex with whom you trust without using condom", "masturbation", "kissing", "body to body touching", and "abstinence", practice of safer sex was also assessed by asking the students to select the options in the awareness section which they practiced.

A list of reasons for which young people engage in premarital sex was also provided and the respondents selected those reason that most correctly described why they practice premarital sex. The data was analyzed using SPSS version 16 by SPSS Inc. Out of the 400 questionnaires that were distributed, 392 were returned for analysis giving a 98\% response rate. Proportions and percentages were computed and reported. Comparisons were made using $\mathrm{Z}$ test to compare the difference between two proportions and chi-squared test was used to check for association or relationship between two variables. Significant differences were set at $95 \%$ confidence limit and $\mathrm{P}$ value of $<0.05$.

\section{Results}

Our results showed that out of 392 student, 154 (39.3\%) were males and $238(60.7 \%)$ were females. The mean age and standard deviation was 17.1 \pm 1.6 . Most respondents were Christians 391 (99.7\%) while one person (0.3\%) was a Muslim. One hundred and 
sixty one (41.1\%) of the students were in Senior Secondary class one, 228 (58\%) in Senior Secondary class two while there were only three students in Senior Secondary class three, (Table 1). One hundred and eight (27.6\%) of the 392 respondents had engaged in premarital sex. Out of the 108 students who engage in premarital sex, males $58(37.7 \%)$ were more than females 50 (21.0\%). Among the 108 students who engage in premarital sex, reasons given for the first episode of premarital sex include "falling in love" 47 (43.5\%), "sexual desire" 17 (15.7\%), "pressure from partner" 16 (14.8\%), while others were "curiosity" one (0.9\%), "peer pressure" four (3.7\%), "rape" seven (6.5\%) and "sex for passing exams" two (1.9\%), (Table 2). Of the 108 students who engage in premarital sex, the 18-20 years age group was the highest with a proportion of $62(44.9 \%)$, followed by the $15-17$ years age group $35(15.2 \%)$ and least in the 12-14 years age group 4 (28.6\%), (Table 3). Amongst students who practice premarital sex, $24(22.2 \%)$ had sex at most twice within the three months preceding the study period while $16(14.8 \%)$ had sex at least twice within the three months preceding the study period. Within the three months preceding the study, 21 (19.4\%) of the 108 students who engage in premarital sex reported having one sexual partner, while $20(18.6 \%)$ reported having multiple sexual partners. Of the 108 students, 32 (29.6\%) used condom during the last episode of sexual intercourse while $76(70.4 \%)$ did not use condom (Table 4). Among the 392 respondents, only $172(43.9 \%)$ were aware of safer sex and out of that 172, $98(57.0 \%)$ had correct knowledge of what safer sex is. Those who have had premarital sex were more likely to be aware of safer sex practices than those who have not had premarital sex. In the same manner, those who have had premarital sex were more likely to have correct knowledge of safer sex practices than those who have not had sex. The students knew about safer sex practices. Out of the 392 students, the proportion who knew about use of condom for safer sex was $66(38.4 \%)$, abstinence as a safer sex practice $8(4.7 \%)$, masturbation as a safer sex practice 35 (20.3\%), body to body touching without fluid exchange as safer sex practice $30(17.4 \%)$,

\begin{tabular}{|c|c|c|c|}
\hline \multirow{2}{*}{$\begin{array}{c}\begin{array}{c}\text { Demographic } \\
\text { characteristics }\end{array} \\
\text { Age group (yrs) } \\
\end{array}$} & \multicolumn{2}{|c|}{ Gender } & \multirow[b]{2}{*}{ Total } \\
\hline & Male & Female & \\
\hline & Frequency (\%) & Frequency (\%) & \\
\hline $12-14$ & $6(3.9 \%)$ & $8(3.4 \%)$ & $14(3.6 \%)$ \\
\hline $15-17$ & $69(44.8 \%)$ & $162(68.1 \%)$ & $231(58.9 \%)$ \\
\hline $18-20$ & $74(48.1 \%)$ & $64(26.9 \%)$ & $138(35.2 \%)$ \\
\hline $21-23$ & $5(3.2 \%)$ & $4(1.7 \%)$ & $9(2.3 \%)$ \\
\hline Total & $154(100 \%)$ & $238(100 \%)$ & $392(100 \%)$ \\
\hline $\begin{array}{c}\text { Mean age (standard } \\
\text { deviation) }\end{array}$ & \multicolumn{2}{|c|}{$17.1(1.6)$} & \\
\hline Religion & \multicolumn{2}{|c|}{ Gender } & Total \\
\hline \multirow[t]{2}{*}{ Christian } & Male & Female & \\
\hline & $154(100 \%)$ & $237(99.6 \%)$ & $391(99.7 \%)$ \\
\hline Muslim & $0(0.0 \%)$ & $1(0.4 \%)$ & $1(0.3 \%)$ \\
\hline Total & $154(100 \%)$ & $238(100 \%)$ & $292(100 \%)$ \\
\hline \multicolumn{4}{|l|}{ Class } \\
\hline SS1 & $57(37.0 \%)$ & $104(43.7 \%)$ & $161(41.1 \%)$ \\
\hline ss2 & 97 (63.0\%) & $131(55 \%)$ & $228(58.2 \%)$ \\
\hline ss3 & $0(0.0 \%)$ & $3(1.3 \%)$ & $3(0.8 \%)$ \\
\hline Total & $154(100 \%)$ & $238(100 \%)$ & $392(100 \%)$ \\
\hline
\end{tabular}

Table 1: Demographic characteristics of the respondents. and kissing as a safer sex practice 33 (19.2\%), (Table 5). Reasons for practicing premarital sexual behavior as reported by the 108 students who engage in premarital sex were many and in different proportions such as exposure to eroticism 127 (32.4\%), molestation during childhood 22 (5.6\%), peer pressure $58(14.8 \%)$, sexual desire 63 (16.0\%), religion $55(14.0 \%)$, family $23(5.9 \%)$, culture $10(2.6 \%)$, and self pledge $34(8.7 \%)$, (Table 6).

\begin{tabular}{|c|c|c|c|c|}
\hline & \multicolumn{2}{|c|}{ Gender } & \multirow[t]{2}{*}{ Total } & \multirow{2}{*}{ Statistics } \\
\hline & $\begin{array}{l}\text { Frequency } \\
(\%)\end{array}$ & $\begin{array}{l}\text { Frequency } \\
\quad(\%)\end{array}$ & & \\
\hline $\begin{array}{c}\text { Have you had sex in } \\
\text { the past }\end{array}$ & Male & Female & & $X^{2}$ test \\
\hline Yes & $58(37.7 \%)$ & $50(21.0 \%)$ & $108(27.6 \%)$ & \\
\hline No & $96(62.3 \%)$ & $188(79.0 \%)$ & $284(72.4 \%)$ & $x^{2}=21.99$ \\
\hline Total & $154(100 \%)$ & $\begin{array}{c}238 \\
(100.0 \%)\end{array}$ & $392(100 \%)$ & $P=0.0004$ \\
\hline \multicolumn{5}{|l|}{$\begin{array}{l}\text { Reasons for first } \\
\text { sexual intercourse }\end{array}$} \\
\hline Curiosity & $0(0.0 \%)$ & $1(2.0 \%)$ & $1(0.9 \%)$ & \\
\hline Fell in love & $22(37.9 \%)$ & $25(50 \%)$ & 47 (43.5\%) & \\
\hline Sexual desire & 15 (25.9\%) & $2(4.0 \%)$ & $17(15.7 \%)$ & \\
\hline $\begin{array}{l}\text { Pressure from } \\
\text { partner }\end{array}$ & $11(19.0 \%)$ & $5(10.0 \%)$ & $16(14.8 \%)$ & \\
\hline Sex for money & $2(3.4 \%)$ & $1(2.0 \%)$ & $3(2.8 \%)$ & \\
\hline $\begin{array}{l}\text { Peer pressure/ } \\
\text { friends }\end{array}$ & $2(3.4 \%)$ & $2(4.0 \%)$ & $4(3.7 \%)$ & \\
\hline Rape & $1(1.7 \%)$ & $6(12.0 \%)$ & $7(6.5 \%)$ & \\
\hline $\begin{array}{l}\text { Sex for passing } \\
\text { exams }\end{array}$ & $1(1.7 \%)$ & $1(2.0 \%)$ & $2(1.9 \%)$ & \\
\hline Others & $0(0.0 \%)$ & $1(2.0 \%)$ & $1(0.9 \%)$ & \\
\hline No response & $4(6.9 \%)$ & $6(12.0 \%)$ & $10(9.3 \%)$ & \\
\hline Total & $58(100 \%)$ & $50(100 \%)$ & $108(100 \%)$ & \\
\hline
\end{tabular}

Table 2: Sexual activity and reason for first sexual intercourse.

\begin{tabular}{|c|c|c|c|c|}
\hline \multicolumn{5}{|c|}{ Practice of Premarital sex } \\
\hline Age & Yes (number/\%) & No (number/\%) & Total & Statistics \\
\hline $12-14$ & $4(28.6 \%)$ & $10(71.4 \%)$ & $14(100)$ & \\
\hline $15-17$ & $35(15.2)$ & $196(84.8)$ & $231(100)$ & $\mathrm{X}^{2}=39.55$ \\
\hline $18-20$ & $62(44.9)$ & $76(55.1)$ & $138(100)$ & $\mathrm{P}=000001$ \\
\hline $21-23$ & $7(77.8)$ & $2(22.2)$ & $9(100)$ & \\
\hline Total & $108(27.5)$ & $284(72.5)$ & $392(100)$ & \\
\hline
\end{tabular}

Table 3: Premarital sex among the students segregated by age group.

\section{Discussion}

The prevalence of HIV in Ebonyi state is 4.1\% [15]. The fact that close to one third of the students are already sexually active in a state with such HIV prevalence rate has implications on adolescent health because this group are likely to engage in risky sexual behavior that can predispose them to HIV/AIDS and other sexually transmitted infection. Data shows that the prevalence of HIV in the age group of $15-24$ in Nigeria is $4.2 \%$ [15]. One can easily relate it to the risk of contracting HIV among this age group with each unsafe sex. The proportion of males (37.7\%) who are sexually active was significantly higher than the females (27.6\%). A study done in Ibadan showed the same trend of sexual activity being higher in boys (39\%) than in girls (13\%) [16]. Also, Egbochukwu reported higher inclination towards 


\begin{tabular}{|c|c|c|c|c|}
\hline & \multicolumn{2}{|c|}{ Gender } & Statistics & \\
\hline $\begin{array}{c}\text { Frequency of sexual } \\
\text { intercourse in the last } \\
\text { 3 months }\end{array}$ & Males & Females & Total & \\
\hline Nil & $35(60.3 \%)$ & $33(66.0 \%)$ & $68(63.0 \%)$ & \\
\hline $\mathbf{1 - 2}$ & $10(17.2 \%)$ & $14(28.0 \%)$ & $24(22.2 \%)$ & \\
\hline$>2$ & $13(22.5 \%)$ & $3(6.0 \%)$ & $16(14.8 \%)$ & \\
\hline Total & $58(100 \%)$ & $50(100 \%)$ & $108(100 \%)$ & \\
\hline $\begin{array}{c}\text { Number of sexual } \\
\text { partners in the last 3 } \\
\text { months }\end{array}$ & $33(56.9 \%)$ & $34(68.0 \%)$ & $67(62.0 \%)$ & \\
\hline Nil & $11(19.0 \%)$ & $10(20.0 \%)$ & $21(19.4 \%)$ & \\
\hline $\mathbf{1}$ & $14(24.1 \%)$ & $6(12.0 \%)$ & $20(18.6 \%)$ & \\
\hline$>1$ & $58(100 \%)$ & $50(100 \%)$ & $108(100 \%)$ & \\
\hline Total & & & & \\
\hline $\begin{array}{c}\text { Condom use during } \\
\text { the last intercourse }\end{array}$ & $17(29.3)$ & $15(30)$ & $32(29.6)$ & \\
\hline Yes & $41(70.7)$ & $35(70)$ & $76(70.4)$ & \\
\hline No & $58(100)$ & $50(100)$ & $108(100)$ & $X^{2}=0.01$, \\
\hline Total & & & & \\
\hline Table 4: Frent
\end{tabular}

Table 4: Frequency of premarital sex and condom use.

early sexual activity in boys than in girls [17]. Higher prevalence of premarital sex among the males has been related to such mistaken beliefs that men's sexual needs are beyond their control and demand immediate satisfaction [18] and the unequal gender norms that perpetuate a sense of entitlement to sex among young men [19]. This notion reflects the double standards in which virginity is the traditional norm for unmarried girls while young men are expected to be involved in sexual adventure [19]. The students gave reasons for engaging in their first sexual intercourse and the most common reason was being in love, followed by sexual desire and pressure from partner. A qualitative study using focus group discussion done in four states in Nigeria also showed peer pressure, sex for gift/cash/favour, coercion includes rape as reasons why adolescents engaged in their first sexual experience [4]. Our study shows that $6.5 \%$ of the students reported rape as a reason for the first episode of sex. Sexual coercion and rape have been previously reported in Sub-Saharan African communities $[20,21]$. Rape may be under-reported in this study probably because it is considered shameful and hence remains secrete [22]. Another study done by Kazaura et al., revealed that $12.2 \%$ of unmarried adolescents reported rape as reason for the first sex [3]. It is possible that if the stigma attached to rape is removed, many more victims may likely report it and the perpetrators punished. All of this uncovers the need to develop strategies that can help adolescents delay onset of sex or even to abstain until marriage.

Our study also showed that a significant proportion of those who were sexually active did not use condom the last time they had sex. This has public health implications for adolescents in a state with HIV prevalence of $4.1 \%$ [15]. It has been reported that the risk of contracting HIV during a sexual exposure with an infected person is between 4 and 138 per 10000 exposures [18]. This is an important information for those who design the curriculum of Secondary schools so that they can strengthen the efforts made in providing information and counseling on HIV and safer sex practices, and delaying onset of premarital sex for Secondary school students. For instance, Namibia as a country has shown that increasing the comprehensive HIV prevention knowledge is associated with the drop

\begin{tabular}{|c|c|c|c|c|}
\hline & Male & Female & Total & Statistics \\
\hline $\begin{array}{l}\text { Awareness of } \\
\text { safer sex }\end{array}$ & $\begin{array}{l}\text { Frequency } \\
(\%)\end{array}$ & $\begin{array}{l}\text { Frequency } \\
(\%)\end{array}$ & & \\
\hline Yes & 78 (50.6\%) & 94 (39.5\%) & $172(43.9 \%)$ & \multirow{3}{*}{$\begin{array}{l}X^{2}=4.72 \\
P=0.0297\end{array}$} \\
\hline No & 76 (49.4\%) & $144(60.7 \%)$ & $220(56.1 \%)$ & \\
\hline Total & $154(12.3 \%)$ & $238(15.5 \%)$ & $392(14.3 \%)$ & \\
\hline \multicolumn{5}{|l|}{$\begin{array}{l}\text { Correct knowl- } \\
\text { edge on safer } \\
\text { sex }\end{array}$} \\
\hline Yes & 41 (52.6\%) & 57 (60.6\%) & $98(57.0 \%)$ & \multirow{3}{*}{$\begin{array}{l}X^{2}=1.13 \\
P=0.2869\end{array}$} \\
\hline No & $37(47.4 \%)$ & 37 (39.4\%) & $74(43.0 \%)$ & \\
\hline Total & 78 (100\%) & $94(100 \%)$ & $172(100 \%)$ & \\
\hline \multicolumn{5}{|c|}{ Premarital sex practice } \\
\hline $\begin{array}{l}\text { Awareness of } \\
\text { safer sex }\end{array}$ & Yes & No & Total & \\
\hline Yes & 92 & 80 & 172 & \multirow{3}{*}{$\begin{array}{l}X^{2}=103.29 \\
P=0.000001\end{array}$} \\
\hline No & 16 & 204 & 220 & \\
\hline Total & 108 & 284 & 392 & \\
\hline $\begin{array}{l}\text { Correct knowl- } \\
\text { edge of safer sex }\end{array}$ & Yes & No & Total & \\
\hline Yes & 78 & 20 & 98 & \multirow{3}{*}{$\begin{array}{l}X^{2}=27.52, \\
P=0.0000\end{array}$} \\
\hline No & 30 & 44 & 74 & \\
\hline Total & 108 & 64 & 172 & \\
\hline \multicolumn{5}{|c|}{ Safer sex practices known by the students } \\
\hline $\begin{array}{c}\text { Barrier } \\
\text { method(condom) }\end{array}$ & $36(46.2 \%)$ & 30 (31.9\%) & $66(38.4 \%)$ & \\
\hline Abstinence & $2(2.6 \%)$ & $6(6.4 \%)$ & $8(4.7 \%)$ & \\
\hline masturbation & $15(19.2 \%)$ & $20(21.3 \%)$ & $35(20.3 \%)$ & \\
\hline $\begin{array}{l}\text { Body to body } \\
\text { touching }\end{array}$ & $12(15.3 \%)$ & $18(19.2 \%)$ & $30(17.4 \%)$ & \\
\hline Kissing & $13(16.7 \%)$ & $20(21.2 \%)$ & $33(19.2 \%)$ & \\
\hline Total & $78(100 \%)$ & 94 (100\%) & $172(100)$ & \\
\hline
\end{tabular}

Table 5: Awareness, knowledge of safer sex practices and safer sex practices known by the respondents.

in the number of people having sex before the age of 15 years and also in the number of people reporting multiple sexual partners [23]. This education becomes very important because only $43 \%$ of the students were aware of safer sex practices and out of that proportion, slightly above half had the correct knowledge of safer sex practices. However, those who were already sexually active were more likely to be aware of safer sex practices and to have correct knowledge of safer sex than those who were not sexually active. It calls for an urgent attention to be paid in strengthening the efforts already being made in the area of teaching sex education in the school system. This result should stimulate concern considering the consequences of unsafe premarital sexual practice which include unwanted teenage pregnancy and possible drop out from school, sexually transmitted infections and HIV [1]. More so when people do not know that what they think is safer sex is not safe, they might put themselves in harm's way. They might also recommend it to their friends and the wrong information and practice continue to spread. The students also mentioned some reasons for the practice of premarital sex. Exposure to eroticism through television, internet, magazine, sexual desire, peer pressure and religion ranked in descending order respectively as reasons why the student practices sex before marriage or not. This information has some important implications. One is that it reveals the contribution of exposure to erotic sites through television, magazines pictures and 
Citation: Chihurumnanya A, Lawrence UO, Benedict NA, Uche D, Nnenna ALO (2016) Premarital Sex, Safer Sex and Factors Influencing Premarital Sex Practices Among Senior Secondary School Students in Ebonyi Local Government Area of Ebonyi State Nigeria. J Community Med Public Health Care 3: 012.

\begin{tabular}{|c|c|c|c|}
\hline & Frequency (\%) & Frequency (\%) & \\
\hline Factors & Males & Females & Total \\
\hline $\begin{array}{c}\text { Exposure to eroticism } \\
\text { through television, } \\
\text { magazine and internet }\end{array}$ & $60(38.9 \%)$ & $67(28.2 \%)$ & $127(32.4 \%)$ \\
\hline $\begin{array}{c}\text { Assault/molestation } \\
\text { during childhood }\end{array}$ & $7(4.6 \%)$ & $15(6.3 \%)$ & $22(5.6 \%)$ \\
\hline Peer pressure & $20(12.9 \%)$ & $38(15.9 \%)$ & $58(14.8 \%)$ \\
\hline Sexual desire & $30(19.5 \%)$ & $33(13.9)$ & $63(16.0)$ \\
\hline Religion & $18(11.7 \%)$ & $37(15.6)$ & $55(14.0)$ \\
\hline Family & $7(4.6)$ & $16(6.7)$ & $23(5.9 \%)$ \\
\hline Culture & $0(0.0 \%)$ & $10(4.2)$ & $10(2.6)$ \\
\hline Self pledge/control & $12(7.8)$ & $22(9.2)$ & $34(8.7)$ \\
\hline Total & $154(100 \%)$ & $238(100 \%)$ & $382(100 \%)$ \\
\hline
\end{tabular}

Table 6: Reasons for practicing premarital sex as reported by the students.

internet to the practice of premarital sex among adolescents. Secondly it provides an opportunity to reach out to them easily having known what they engage in. This will also help in knowing what to focus on when counseling adolescents on sex. Moreover it also reveals other areas that could be exploited in providing help and counseling to adolescents such as self pledge, family and culture. These had low reporting frequencies as reasons for premarital sex practice but then they might still be used to positively enhance the disposition of adolescents towards premarital sex. Other studies have also shown some of these factors as influencing premarital sex [6,7].

\section{Conclusion}

Premarital sex was practiced among the students yet few of them knew and practiced safer sex. Males were significantly more likely to engage in premarital sex than females in the adolescent period. The most prevalent reason why they practiced premarital sex was exposure to eroticism through television, magazines and the internet.

\section{References}

1. Finer LB (2007) Trends in premarital sex in the United States, 1954-2003. Public Health Rep 122: 73-78.

2. Kumar GA, Dandona R, Prem kumar SG, Dandona L (2011) Behavioral surveillance of premarital sex among never married young adults in a high HIV prevalence district in India. AIDS Behav 15: 228-235.

3. Kazaura MR, Masatu MC (2009) Sexual practices among unmarried adolescents in Tanzania. BMC Public Health 9: 373.

4. Ankomah A, Mamman-Daura F, Omoregie G, Anyanti J (2011) Reasons for delaying or engaging in early sexual initiation among adolescents in Nigeria. Adolesc Health Med Ther 2: 75-84.

5. Morhason-Bello IO, Oladokun A, Enakpene CA, Fabamwo AO, Obisesan KA et al. (2008) Sexual behaviour of in-school adolescents in Ibadan, SouthWest Nigeria. Afr J Reprod Health 12: 89-97.

6. Santelli JS, Kaiser J, Hirsch L, Radosh A, Simkin L, et al. (2004) Initiation of sexual intercourse among middle school adolescents: the influence of psychosocial factors. J Adolesc Health 34: 200-208.
7. World Health Organisation (2007) Global Strategy for the Prevention of and Control of Sexually Transmitted Infections: 2006-2015. Breaking the chain of transmission. World Health Organization, Geneva, Switzerland.

8. Public Health Agency of Canada (1998) STI Epi Update: Oral Contraceptive and Condom Use. Public Health Agency of Canada, Canada.

9. Moskowitz JM, Ritieni A, Tholandi M, Xia Q (2006) How do Californians define safe sex? Californian Journal of Health Promotion 4: 109-118.

10. World Health Organisation, Department of Child and Adolescent Health and Development World Health Organization, Regional Office for Africa (2001) Strengthening the provision of adolescent-friendly health services to meet the health and development needs of adolescents in Africa : a consensus statement. World Health Organization, Geneva, Switzerland

11. UNDO/UNFPA/WHO (2003) Special Program of Research Development and Research Training in Human Reproductive Health (HRP), Progress in Reproductive Health Research. World Bank No-64, World Health Organization, Geneva, Switzerland.

12. Mensch B S, Clark WH, Lloyd CB, Erulkar AS (2001) Premarital sex, schoolgirl pregnancy, and school quality in rural Kenya. Stud Fam Plann 32: 285301.

13. Kabiru CW, Orpinas $P$ (2009) Factors associated with sexual activity among high-school students in Nairobi, Kenya. Journal of adolescence 32: 10231039.

14. Oladepo O, Fayemi MM (2011) Perceptions about sexual abstinence and knowledge of HIVIAIDS prevention among in-school adolescents in a western Nigerian city. BMC Public Health 11: 304.

15. National Agency for the control of AIDS (2012) Federal republic of Nigeria global AIDS response Country progress report. Federal Ministry of Health Abuja, Nigeria.

16. Bamidele JO, Abodunrin OL, Adebimpe WO (2009) Sexual behavior and risk of HIVIAIDS among adolescents in public secondary schools in Osogbo, Osun State, Nigeria. Int J Adolesc Med Health 21: 387-394.

17. Egbochuku E, Omotunde E, Imo B (2008) Attitude of Nigerian Secondary School Adolescents Toward Sexual Practices: Implications For Counselling Practices. European Journal of Scientific Research 22: 177-179.

18. Federal Ministry of Health (2006) National HIVIAIDS and Reproductive Health survey (NARHS): Nigeria 2005. Federal Republic of Nigeria, Federal Ministry of Health, Nigeria.

19. Kirby D (2007) Emerging answers 2007 - Research findings on programs to reduce teen pregnancy and Sexually Transmitted Diseases. National Campaign to Prevent Teen and Unplanned Pregnancy, Washington DC, USA

20. Wood K, Lambert H, Jewkes R (2007) "Showing roughness in a beautiful way": talk about love, coercion, and rape in South African youth sexual culture. Med Anthropol Q 21: 277-300.

21. Erulkar AS (2004) The experience of sexual coercion among young people in Kenya. Int Fam Plan Perspect 30: 182-189.

22. Centers for Disease Control and Prevention (2014) HIV transmission risk HIVIAIDS, Guidelines and Recommendations, Centers for Disease Control and Prevention, Atlanta, USA.

23. Coates TJ, Richter L, Caceres C (2008) Behavioural strategies to reduce HIV transmission: how to make them work better. The Lancet 372: 669-684. 